\title{
A decrease in eating barnyard millet in Iwate prefecture: a literature review of Iwate no Hoken (hygiene in Iwate)
}

\author{
Takahiro Mitsui
}

\begin{abstract}
Although it is not used today, barnyard millet and foxtail millet were staples, especially for people living in the cold and mountainous areas in Japan. The Northern part of Iwate prefecture was the largest area for barnyard millet production, but its production had almost disappeared up to the late 1960s during the high economic growth period. The disused process and how people felt along with the mood during that time are not well examined. Articles in Iwate no Hoken (hygiene in Iwate), a local journal that was published by the Iwate prefecture National Health Insurance Organization from the mid-1950s to the late 1960s, were examined. This journal was mainly composed of a reader's column or letters about every aspect of daily life, such as medicine, family problems, diet, education, culture, business, and readers' autobiographies. Many articles indicated that people hid the fact that they ate millet. The rapid shift from millet to rice was accompanied by a change in their community from a selfsufficient society to a consuming society. The pleasure of eating white rice seemed to be fully suppressed by their financial problems regarding buying electric products, agricultural equipment, motorcycles, and food. Many laborers had to work outside of their hometown and the younger generation, especially girls, left their community. The editorial office concluded that the self-sufficient society had become a consuming society.
\end{abstract}

Keywords: Barnyard millet, Foxtail millet, Rice, Iwate prefecture, Iwate no Hoken (hygiene in Iwate)

\section{Introduction}

Rice is generally considered to be a staple food in Japan [1]. The Japanese diet is considered to comprise rice, miso soup, soybean products, vegetables, fish, pickles, seaweed, and mushrooms, and it has been recognized as a healthy diet, which contributes to longevity $[2,3]$. Although it is obsolete today, barnyard millet and foxtail millet were important crops. Yabuno [4] summarized barnyard millet in a modern Japanese history as follows:

Japanese barnyard millet has been grown in the district in Japan where soil, weather conditions, and irrigation systems were not suitable for paddy rice cultivation. Millet, which is resistant to cool weather, prevented

Correspondence: mitsui@iwate-u.ac.jp

Department of Home Economics, Faculty of Education, Iwate University, 3-18-33 Ueda, Morioka, Iwate 020-8550, Japan starvation in years when the rice crop suffered serious damage from cool weather.

Acreages planted with Japanese barnyard millet in Japan are negligible today, having decreased from 103, 600 hectares (ha) in 1880 to 5090 ha in 1969 , and then to 285 ha in 1984 . In the years since around 1925 , the acreage devoted to cultivation of millet in Iwate prefecture has been equivalent to nearly $1 / 2$ the total area for this millet in all of Japan. The northern part of Iwate is characterized by a higher elevation and prevailing upland farming, i.e., Japanese barnyard millet or foxtail milletwheat-soybean rotation. In this region, severe cool weather damage is liable to occur mainly because of the cold sea wind in the summer, and rice has been a luxury food for most of the people for a long time. The people were used to eating Japanese barnyard millet as a substitute for rice or as an extender for rice, usually by mixing rice

(c) The Author(s). 2020 Open Access This article is licensed under a Creative Commons Attribution 4.0 International License, which permits use, sharing, adaptation, distribution and reproduction in any medium or format, as long as you give appropriate credit to the original author(s) and the source, provide a link to the Creative Commons licence, and indicate if changes were made. The images or other third party material in this article are included in the article's Creative Commons licence, unless indicated otherwise in a credit line to the material. If material is not included in the article's Creative Commons licence and your intended use is not permitted by statutory regulation or exceeds the permitted use, you will need to obtain permission directly from the copyright holder. To view a copy of this licence, visit http://creativecommons.org/licenses/by/4.0/. 
with millet in a proportion of 1:1. This diet continued until the 1940s.

The development of rice variation was adapted to cool areas, and the improvement of rice-growing techniques is mainly responsible for the decrease in millet. Iwate prefecture was well known as a horse-breeding center. After the 1950s, the significance of horses for farm labor or transport decreased because of the diffusion of power cultivators and cars. Thus, the number of horses raised by farmers decreased. The change in the situation is also a reason for the remarkable decrease in the area that was devoted to Japanese barnyard millet.

As mentioned above, Iwate prefecture was the largest area of barnyard millet production in Japan, and it is not well known how the people felt about the disused process, especially the change of lifestyle, and how they felt and the mood at that time was not well known.

The Iwate no Hoken (hygiene in Iwate) was published by Iwate prefecture National Health Insurance Organization and edited by Ryo Omura (1909-1993). It was a local journal concerning daily life including medicine, family problems, diet, education, culture, and business in Iwate. The contributors were mainly various kinds of readers, such as doctors, nurses, professors, teachers, farmers, government clerks, students, and housewives. The editor [5] criticized existing journals, either national or local, because the contributors were almost all professional writers or celebrities, while the opinions of unknown people are rare. In addition, their opinions sometimes differed from what they were really thinking because they were forced to adjust to the question that the reporter wanted to be answered.

The articles in Iwate no Hoken seem to be primary material for examining people and the mood at that time. The purpose of this study is to review these articles when barnyard millet rapidly disappeared in Iwate between the mid-1950s and the late 1960s.

\section{Succession of acreage in 1955, 1960, and 1965 in Iwate prefecture}

Acreage that was planted with rice, barnyard millet, and foxtail millet in eight areas in 1955, 1960, and 1965 are investigated (Table 1). The areas are as follows: Fukuoka town (the present Ninohe City), Kunohe village, Iwaizumi town, Taneichi town (the present Hirono town), Morioka City, Hanamaki City, Tono City, and Ichinoseki City (Fig. 1). These data were included in the Statistical Handbook of Iwate of each year. Extensive merging of cities, towns, and villages was overseen from 1953 to 1955, which makes it difficult to obtain the data before 1955 .

In 1955, millet cultivation was predominant in the northern part of Iwate especially in Iwaizumi's mountainous area. However, paddy fields were predominant in the center and southern part of Iwate, but millet was cultivated to some extent, except in Ichinoseki, which is well-known for its rice-cake culture [6]. The proportion of acreage for millet decreased in all areas, and little remained in the middle and southern areas in 1965. Although the statistics for millet have not been available since 1967, the production seemed to continue for a while in the northern area.

\section{Main staple from the mid-1950s to mid-1960s in the northern part of Iwate prefecture}

The editorial office [7] conducted a questionnaire survey of 22 readers who lived in different areas in Iwate prefecture about their dietary habits in 1955. Except for three middle and southern rural communities, their staples were a mix of rice, barnyard millet, foxtail millet, and barley. In this article, the editor recalled that there were many students who ate barnyard millet that was contained in a cloth sack at lunch when he was a teacher at a primary school in this area around 1935. Barnyard millet is not sticky even when it is boiled, so a lunch box is not suitable for carrying it. He assumed that the food

Table 1 Acreage planted with paddy fields (P), barnyard millet (B), and foxtail millet (F) in eight areas in Iwate prefecture in 1955, 1960, and 1965

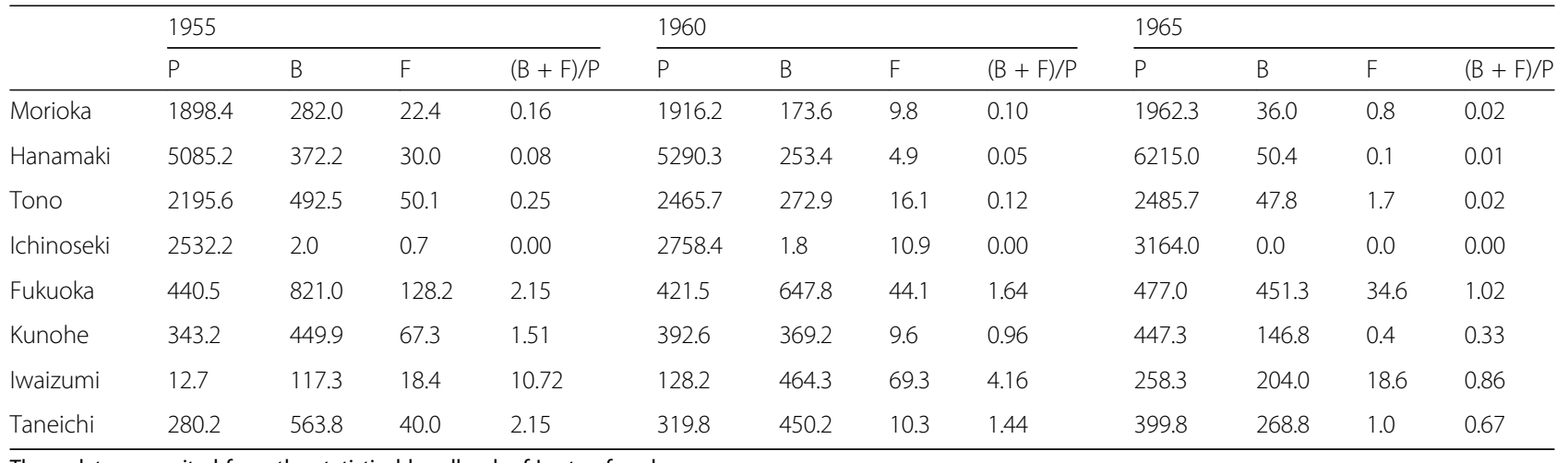

These data were cited from the statistical handbook of Iwate of each year

The unit of acreage is a hectare. The original units are in chobu in 1955 and 1960, and acre in 1965

Minor merging with neighboring cities, towns, and villages occurred during this period 


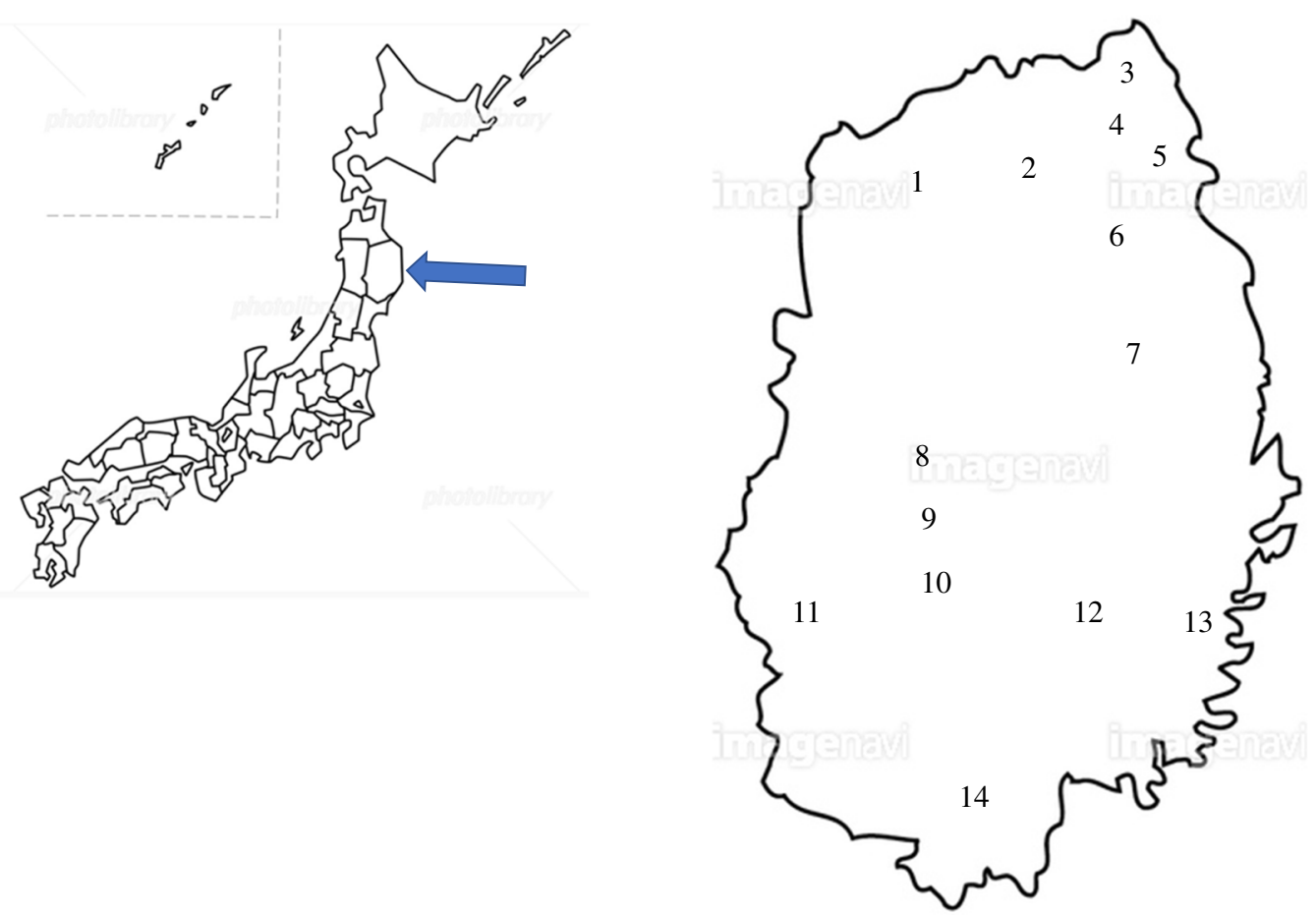

1. Fukuoka

2. Kunohe

3. Taneichi

4. Yamane

5. Kuji

6. Kuzumaki

7. Iwaizumi

8. Morioka

9. Akaishi

10. Hanamaki

11. Waga

12. Tono

13. Kamaishi

14. Ichinoseki

Fig. 1 Iwate prefecture is located in northern Japan. It is the second-largest prefecture, next to Hokkaido. This map shows 14 cities, towns, and villages that appear in the text. Morioka City is the geographic, political, and cultural center. Most of the land of the northern district was inadequate for rice cultivation because of the high altitude and cool weather in summer, which is mainly because of Yamase, a foggy sea wind. The southern districts are rather geographically plain, and rice has been a staple, except for in the mountainous area

habits around the area had greatly changed in the last 20 years. A possible cause was rationing during and after the World War II, which changed eating habits; people started eating rice, fish, seaweeds, and sugar.

Harue Hosono [8], a 19-year-old woman in Kunohe District, submitted an article entitled "Daily life in poverty" in 1960 (Fig. 2a). Her family, parents, and three young brothers and a sister made their living on an approximately 1-hectare (ha) field, cultivating 0.4 ha for barnyard millet, 0.4 ha for beans and wheat, and the rest was foxtail millet and buckwheat. They had no paddy fields or domestic animals. They usually ate a mix of millet and rice, the ratio of which was varied ( $70 \%$ millet and $30 \%$ rice), and sometimes all millet. When the harvest was poor, the millet would run out by the end of June. At that time, her father asked relatives and (a)

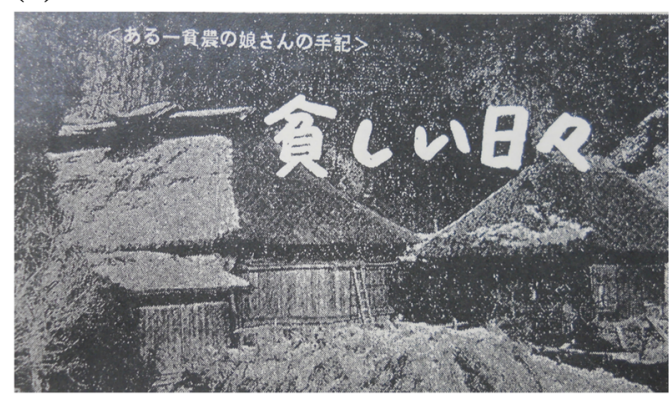

(b)

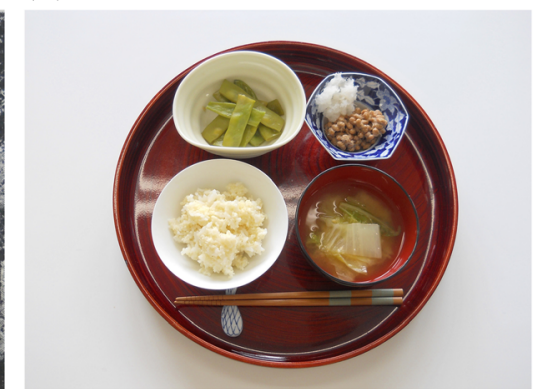

Fig. 2 A typical small-scale farmer's house (a) and a supper (b) in the northern district of Iwate around 1960 [8]. The supper was cooked by the author, referring to the text. The house was made of a straw-thatched roof and wooden board walls without windows. Therefore, the room was very dark even in the daytime. A bowl of mixed millet and rice in a proportion of 1:1 is pictured with the following side dishes: fermented soybeans (natto) with grated radish, boiled rabbit beans in soy sauce, and Chinese cabbage miso soup. In those days, farmers in Iwate prefecture were basically self-sufficient for their food, but this means that their diet was quite simple. They rarely ate animal products such as meat, eggs, and milk. Eating fish as part of daily life started after rationing during the World War II, except for in the coastal area 
acquaintances to borrow money, but in most cases, they refused.

Barnyard millet, their lifeline crop, had seriously been damaged by a typhoon before harvesting in late September in each of the last 2 years (Kanogawa typhoon [typhoon Ida] and Isewan typhoon [typhoon Vera]). Although her parents harvested the crops throughout the day and night in the strong wind, they could not complete the harvest. She looked after her crying younger brothers and sister in the rain in a house with a leaking straw-thatched roof. The harvests were less than half in 1958 and $60-70 \%$ in 1959 compared to those of an average year.

She sometimes thought that if she worked at a night entertainment business in Tokyo like her ex-classmate, she could make money and sent some to her family. If so, her family's life would be easier, with no worries about food, paying school fees for her brothers, sometimes eating fish, and obtaining tobacco for her father.

The supper side dishes were fermented soybeans (natto) with grated radish, boiled rabbit beans in soy sauce, and Chinese cabbage miso soup (Fig. 2b). The breakfast side dishes were tofu and radish miso soup and radish pickles. She preferred hot millet rice to white rice, and wondering why people loved white rice so much.

Isao Hatakeyama [9], a 25-year-old farmer in the Kunohe area recalled his dietary habits in response to the questionnaire by the editorial office in 1969 . He answered that it was fun to have lunch at school because he could eat white rice, and his family had white rice several times a year at home in those days.

The editor [7] also felt that it was difficult to collect accurate dietary records because people eating barnyard millet as a staple did not like to talk about their diet. A farmer woman replied to the interviewer of a national nutrition survey that started in 1948 that it is shameful to respond honestly, so she usually answered the questions appropriately. A nurse said that she could distinguish between a child eating rice or barnyard millet at home because the latter used chopsticks too quickly even when they ate rice.

\section{Overeating rice in Akaishi village in the central part of Iwate prefecture}

Shoji Kondo [10], Honorable Professor of Public Health at Tohoku University, gave a lecture at the Iwate prefecture National Health Insurance Organization. The speech was printed in three successive volumes in 19561957. He researched the dietary habits and incidence of people who were $>70$ years old in 1955 in the following five local communities in Akaishi village, Shiwa district: Inubuch, Sakuramachi, Kitahizume, Minamihizume, and Hirasawa. The incidence of people who were $>70$ years old was very low from (0 to $1.4 \%$ ), except for in the
Hirasawa community, where the incidence was $3.5 \%$. Besides Hirasawa, four communities mainly cultivated paddy fields. Thus, residents of Hirasawa ate a lot of millet, vegetables, and soybeans, while people in the four communities filled their stomachs with rice. Although they produced beans, they did not eat them because they were for selling and feeding the horses. Japan was a short-lived nation, with $2.7 \%$ of people $>70$ years old, which is much lower than other developed nations, such as Britain, Sweden, France, and Germany, where this age group represents $5-6 \%$ in the population. A possible cause is overeating rice and salt mainly from miso soup and pickles, which are closely associated with a high incidence of stroke. Prof. Kondo recommended that people should eat up to $3 \mathrm{go}(450 \mathrm{~g}, 1620 \mathrm{kcal})$ of rice in a day, and more of the other side dishes such as vegetables, soybean, seaweed, butter, and cow's milk should be eaten.

\section{Food habits in the mountainous charcoal-making town, Iwaizumi, in 1959 and 1962}

Barnyard millet is generally considered to be a crop for the poor around the world. However, those who had land and could produce food themselves ate millet, while those who did not have land ate rice in this region.

Satoru Kinoshita [11], a 25-year-old teacher, reported about charcoal making families in 1959. They needed to buy all their food, and therefore the staple was rice with a little barley and millet. A family of five consumed 2 shou ( $3 \mathrm{~kg}, 600 \mathrm{~g}$, and $2160 \mathrm{kcal}$ per capita) of rice every day and ate fish three or four times per week by buying it from a merchant or by catching it in a river. Because they had to travel from mountain to mountain to cut trees, their mountain huts were small and humble without tatami mats or thresholds between rooms. The floor was made of straw, wooden board, and straw mats that were directly on the ground. Because of the distance and work at home, children were often absent from school, especially on rainy days. They grew up while moving from a small school to a small school on a mountain. Figure 3 shows woodprints, and the text describes their daily lives.

Riwako Takagi [12], a primary school teacher in the charcoal-making town, Iwaizumi, reported food habits and health conditions of pupils and their families in 1962. Almost all children were small and pale. Relatively wealthy children wore tabi (five-toed Japanese socks) instead of shoes or slippers in classroom, while others had bare feet even in winter. The stature of children was much shorter than the prefectural average $(103.7 \mathrm{~cm}$ vs. $110.4 \mathrm{~cm}$ in 6-year-old boys and 104.0 vs. 109.0 in 6 year-old girls). This area had a high incidence of infant death (69.0 per 1000), which was much higher than the prefectural and national average of 52.8 and 34.3 per 1000 , respectively. 
(a)

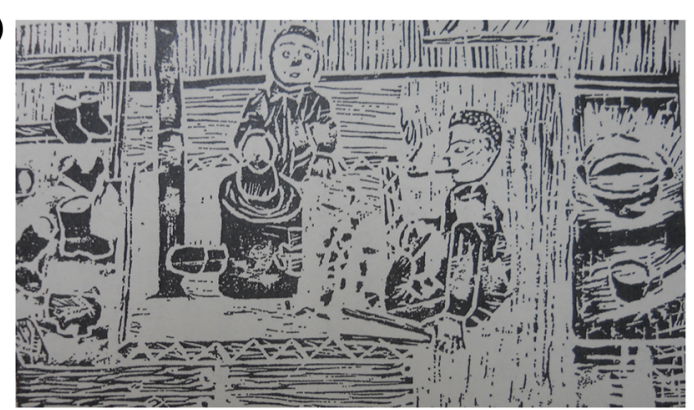

(b)

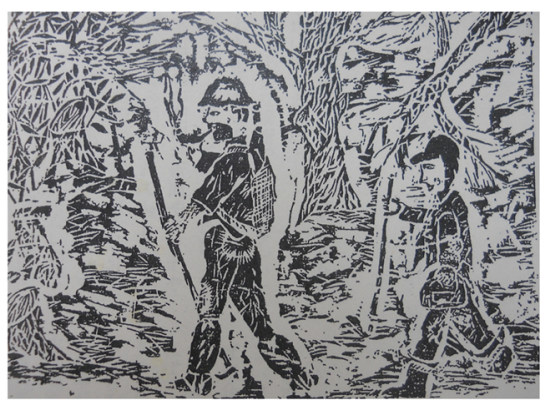

(c)

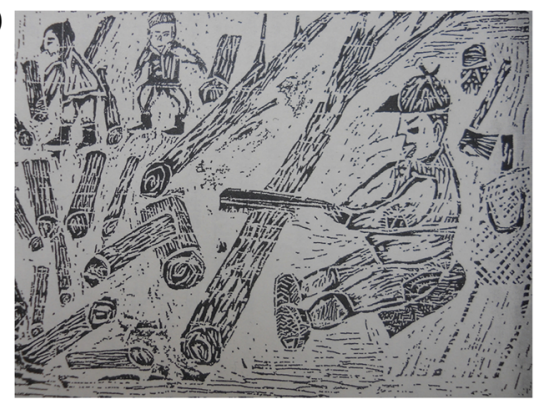

Fig. 3 These woodprints [11] describe the daily life of charcoal farmers. a Their mountain huts were humble without tatami mats and the threshold between rooms. The floor was made of straw, wooden board, and straw mats that were directly on the ground. A woodburning stove at the center of the house was also used for cooking. $\mathbf{b}$ A charcoal-making young couple. They had to walk to a distant area because there were few trees in near (figure click here to access/download;Figure;renamed_5cd68.docx mountain). c A father is cutting a tree and his children are carrying the firewood. Because of the distance to school and work around the home, children were often absent from school

Almost all of the houses were built along the river, and the water was used for drinking. All families made charcoal, and occupations could be divided into three main types: mainly farming, mainly charcoal making, and only charcoal making.

The lunch of children from charcoal families was white rice with some barley, while that of farmers was millet and barley with a little rice. Charcoal families must buy all their food, while farmers could supply themselves except for rice. Some of the farmers' children did not bring a lunch box or they ate a millet lunch with a group at the corner of the school grounds.

The side dishes were usually miso soup and pickles, and sometimes fish and boiled beans or vegetables in soy sauce. Instead of events or festivals, the dishes were a luxury. Tables 2 and 3 describe the menu and nutritional value of a farmer's family with eight members (Table 2) and a charcoal maker's family with four members (Table 3), on the New Year holiday. Their diets basically consisted of rice/barley/millet, miso soup, and pickles, which are starchy and lack animal fat and protein.

\section{Food habits of settlers in the central part of Iwate in 1960}

The Japanese government promoted land reclamation to increase food production and job opportunities for returning soldiers, repatriates from outside the Japanese mainland, and war victims.

Tokuko Mirura [13], a 19-year-old woman in the settlement in Tono City, reported about her life in 1960. Her father was a steel industry employee in Kamaishi City, which was bombed and devastated by the US army in the end of World War II. After the war, they moved there because her parents thought that it would be easier to get food. The settlement consisted of 16 families, and most of them were urban inhabitants before the war, while some of them were repatriates who had nothing. At that time, they lived in a shack made of a galvanized iron roof and wooden board wall, and food was very scarce. Her brothers collected many edible wild plants after school. The wild plants, two bowls of barley, and a little rice were all they had to eat for eight people in her family in a day.

Children living in the settlement were often bullied at school because their clothes and diets were so poor. Most of the settled lands were inadequate for paddy fields because of the lack of irrigation, so wheat, potato, fruit, dent corn, and beets were cultivated. They had to buy expensive rice by selling cheap field crops. Many farmers' incomes were not good because they were forced to pay back loans when they purchased agricultural machinery and other items. Most of them had to work outside of the community for long periods or as 
Table 2 The menu for a farmer's family with eight members and individual nutrient intake on the New Year's holiday in Iwaizumi town

\begin{tabular}{|c|c|c|c|c|c|c|c|c|c|}
\hline & & Ingredients & Total, g & Per capita, g & Energy, kcal & Protein, $\mathrm{g}$ & Fat, $g$ & Carbohydrate, $\mathrm{g}$ & Salt, $g$ \\
\hline \multirow[t]{8}{*}{ Breakfast } & Rice & & 2100 & 262.5 & 939.8 & 16.0 & 2.4 & 203.7 & 0.0 \\
\hline & Miso soup & Miso & 350 & 43.8 & 94.9 & 7.5 & 4.6 & 6.3 & 4.8 \\
\hline & & Tofu & 940 & 117.5 & 94.0 & 8.2 & 5.8 & 1.8 & 0.0 \\
\hline & & Carrot & 350 & 43.8 & 15.8 & 0.3 & 0.0 & 4.1 & 0.0 \\
\hline & & Burdock & 180 & 22.5 & 14.6 & 0.3 & 0.0 & 3.5 & 0.0 \\
\hline & Pickles & Leaf mustard & 300 & 37.5 & 12.4 & 1.1 & 0.1 & 2.6 & 2.2 \\
\hline & Rice cake & & 1000 & 125.0 & 292.5 & 5.0 & 0.8 & 63.5 & 0.0 \\
\hline & Apple & & 520 & 65.0 & 37.1 & 0.1 & 0.1 & 10.1 & 0.0 \\
\hline \multirow[t]{2}{*}{ Lunch } & Rice & Remaining fro & breakfast & & & & & & \\
\hline & Pickles & Leaf mustard & & & & & & & \\
\hline \multirow[t]{10}{*}{ Supper } & Rice & & 700 & 87.5 & 313.3 & 5.3 & 0.8 & 67.9 & 0.0 \\
\hline & Barnyard millet & & 140 & 17.5 & 64.1 & 1.6 & 0.6 & 12.8 & 0.0 \\
\hline & Miso soup & Miso & 200 & 25.0 & 54.3 & 4.3 & 2.6 & 3.6 & 2.7 \\
\hline & & Meat & 1200 & 150.0 & 219.0 & 30.8 & 9.5 & 0.5 & 0.2 \\
\hline & & Dried radish & 300 & 37.5 & 112.9 & 3.6 & 0.3 & 26.1 & 0.2 \\
\hline & & Carrot & 205 & 25.6 & 9.2 & 0.2 & 0.0 & 2.4 & 0.0 \\
\hline & & Burdock & 110 & 13.8 & 8.9 & 0.2 & 0.0 & 2.1 & 0.0 \\
\hline & & Tofu & 380 & 47.5 & 5.9 & 3.3 & 2.3 & 0.7 & 0.0 \\
\hline & Pickles & Radish & 450 & 56.3 & 32.1 & 0.5 & 0.1 & 7.9 & 1.7 \\
\hline & & & & & 2320.0 & 88.4 & 29.9 & 419.6 & 11.8 \\
\hline
\end{tabular}

The menu and weight of ingredients are described in the text. Nutrient values were calculated by the author Nutritional value was calculated by referring to the Standard Table of Food Composition in Japan, 2015 (seventh edition) Meat is assumed to be rabbit meat, which was a local cuisine in the winter season

day laborers to make money. Fortunately, most families started keeping milk cows, and their manure could help to increase wheat production. She had a plan to start a small factory making bread and butter using their products.

Kyoko Sasahara [14], a 19-year-old woman in a settlement in the Waga district, contributed a similar letter in 1960. She wrote of her experiences when she was bullied for her poor appearance and for her bean and millet lunch at school. When she ate lunch, she always hid it with the lid of the lunch box. After graduating junior high school, she started working on an orange farm in Shizuoka prefecture, which was the only choice for her. Two years later, she came back to her hometown and was a student at a sewing school at that time. Even when she wrote the letter, she rarely ate rice. She stated that nothing was crueler than the words "rich and poor," and she felt isolation anywhere because of it.

\section{The small fishery village, a high incidence of laborers outside of the town, Taneichi in 1964}

The number of seasonal or migrant workers from Iwate prefecture, especially the northern district, was very high. One reason is that the feudal land system had remained until the end of World War II. After the war, General Headquarters, the Supreme Commander for the Allied Powers (GHQ) promoted emancipation of farming land. Most of the farmers in this area were released from nago, a feudal peasant, after the war. Because of the small scale and poor soil, they needed to work outside of their hometown. The destination had been predominantly Hokkaido until the mid-1950s. Most of them worked for fishery, forestry, and civil engineering and construction sites, and sent money to their family. The Kuji public job center mediated 2085 jobs in Hokkaido in 1953, which was a cash box for local society [15]. The number of seasonal laborers in the Tokyo area had greatly increased between the early and mid-1960s. They were involved in urban development construction such as the Metropolitan Expressway, Tokaido Shinkansen (Bullet Train), and Tokyo Olympic-related facilities.

Tamotsu Hatakeyama [16], a 23-year-old prefectural male clerk, reported the atmosphere of Taneichi town in 1964. He saw approximately 30 women sowing barnyard millet in a small field in spring. He asked them and knew that this was a labor exchange. He also wondered why there were no men, and doubted, for the first time, that farming was a labor only for women in this 
Table 3 The menu for a charcoal-maker's family with four members and individual nutrient intake on the New Year's holiday in Iwaizumi town

\begin{tabular}{|c|c|c|c|c|c|c|c|c|c|}
\hline & & Ingredient & Total, g & Per capita, $\mathrm{g}$ & Energy, kcal & Protein, $\mathrm{g}$ & Fat, $\mathrm{g}$ & Carbohydrate, $\mathrm{g}$ & Salt, $g$ \\
\hline \multirow[t]{7}{*}{ Breakfast } & Rice & & 1260 & 315.0 & 1127.7 & 19.2 & 2.8 & 244.4 & 0.0 \\
\hline & Barley & & 330 & 82.5 & 285.5 & 5.5 & 1.2 & 64.6 & 0.0 \\
\hline & Miso soup & Miso & 200 & 50.0 & 108.5 & 8.6 & 5.3 & 7.3 & 5.5 \\
\hline & & Potato & 1000 & 250.0 & 190.0 & 4.5 & 0.3 & 43.3 & 0.0 \\
\hline & & Carrot & 90 & 22.5 & 8.1 & 0.2 & 0.0 & 2.1 & 0.0 \\
\hline & & Chinese leaf & 350 & 87.5 & 12.3 & 0.7 & 0.1 & 2.8 & 0.0 \\
\hline & Pickles & Radish & 120 & 30.0 & 17.1 & 0.3 & 0.0 & 4.2 & 0.9 \\
\hline \multirow[t]{4}{*}{ Lunch } & Rice & Remaining fror & breakfast & & & & & & \\
\hline & Barley & & & & & & & & \\
\hline & Natto (fermented soybeans) & & 100 & 25.0 & 50.0 & 4.1 & 2.5 & 3.0 & 0.0 \\
\hline & Soy sauce & & 18 & 4.5 & 3.5 & 0.3 & 0.0 & 0.4 & 0.7 \\
\hline \multirow[t]{8}{*}{ Supper } & Rice & & 560 & 140.0 & 501.2 & 8.5 & 1.3 & 108.6 & 0.0 \\
\hline & Barley & & 100 & 25.0 & 86.5 & 1.7 & 0.4 & 19.6 & 0.0 \\
\hline & Miso soup & Miso & 80 & 20.0 & 43.4 & 3.4 & 2.1 & 2.9 & 2.2 \\
\hline & & Chinese leaf & 180 & 45.0 & 6.3 & 0.4 & 0.0 & 1.4 & 0.0 \\
\hline & & Carrot & 50 & 12.5 & 4.5 & 0.1 & 0.0 & 1.2 & 0.0 \\
\hline & & Dried sardine & 40 & 10.0 & 33.2 & 21.4 & 0.6 & 0.0 & 0.4 \\
\hline & Pickles & & 90 & 22.5 & 12.8 & 0.2 & 0.0 & 3.2 & 0.7 \\
\hline & & & & & 2490.5 & 79.2 & 16.6 & 508.9 & 10.3 \\
\hline
\end{tabular}

community. He realized thereafter that this was because most of men went out of town to work. The disparity between the rich and poor in this district was very large; a few wealthy farmers had 300-ha forests and 3-ha fields, while most of others had only $0.5-1$-ha fields.

In 1963, 494 men from 412 out of 682 families (60.4\%) were working as divers, ship workers, or seasonal laborers outside of the town in eight local communities. He estimated that the number of seasonal laborers had increased since 1955 and would remain high for the near future.

Instead of obtaining cash, there were many negative aspects of working outside of the hometown. The workers were often involved in fatal accidents in their workplace. A long period of absence by a husband/ father created various kinds of family problems. For example, a husband left home for work 2 weeks after a wedding ceremony, and the wife also left home after a while, probably because she did not like to live, and do farm work, with her mother and fatherin-law. Construction work, with the workers following the boss for a long time gradually ruined the professional consciousness of a farmer. After finishing work and returning to the hometown in spring, it was difficult to restart and concentrate on farming probably because of the time away.

\section{Lifestyle changes in the charcoal village, Yamane town, in 1968}

The prevalence of lifelines, such as electricity, gas, and running water, were delayed in mountainous areas in the northern district of Iwate. In addition, public transportation, trains, and buses have been inconvenient and unavailable to date. Yonezo Tsuchikura [17], a 24-yearold farmer, in Kuzumaki town, remembered that electricity had not been available in his community since December 1961. He felt that it gave them a little bit of hope or was something that was good for them.

Mitsue Sekiguchi [18], a 28-year-old farmer's housewife in Yamane town, reported an article about the change of lifestyle in her community in 1968. Her local community was self-sufficient, making a living by agriculture and charcoal-making, but the atmosphere had changed dramatically in the previous 10 years.

It became convenient to use electric lights, bus service, telephones, running water, and propane gas, but they were always talking and worried about money. At that time, they needed to go to a distant area to cut trees because there were few trees on the nearby mountain. However, the price of charcoal was not that different from before because the demand for charcoal had decreased. During modernization of everyday life, millet disappeared, and almost all families needed to buy rice. 
Many men left her town as laborers to go from Hokkaido to Tokyo to pay loans for electric products, agricultural machinery, and motorcycles, and thus, farming was conducted by the remaining women. The younger generation, especially girls, did not like farming, and they left their community. Therefore, the lack of brides was a serious problem.

\section{Dietary questionnaire survey by the editorial office in 1969}

The editorial office [19] conducted a questionnaire survey again about the dietary habits of 44 readers in a different area in 1969. How had the dietary habits changed in the previous 10 years? In the northern area, the mix of millet, barley, and rice had changed to white rice. In the southern area where rice was originally eaten as staple, the diet had changed to some extent, with an increasing amount of noodles and instant foods.

The side dishes were usually home-made pickles, tofu, natto, and wild plants. There were few side dishes at that time. Meat and dairy products such as ham, sausage, liver, butter, and cheese, which were never eaten before, were available. Fresh fish was also available at that time, where before, the fish had been dried. A variety of spices, such as Worcester sauce, mayonnaise, ketchup, and Ajinomono are used today, but only miso, soy sauce, vinegar, and sugar were available at that time. However, home-made miso and pickles are rarely made today. There were no farmers who bought vegetables 10 years ago. They needed to buy vegetables because their fields were turned into paddy fields or used for other cash crops.

Kitchens became clean and bright. Tap water, propane gas, the kitchen sink and table, and various kinds of electrical products were common, which made cooking easier and could save time. However, river and well water, hearths, and iron cauldrons were gone or became rare. Old women who were unable to do farm work were usually responsible for the cooking before, but some of them did not adapt to the modern kitchen equipment. Thus, housewives often cooked for the family instead of them.

\section{Conclusion}

All the articles indicated that people in this region were eager to eat white rice and that eating millet tended to be hidden. The author could not find an article that described the pleasure of eating white rice. One reason is that most of them hid eating barnyard millet, so they started eating white rice, which did not appear in the literature. Another reason is that they were rushed by making money, and working outside of their hometown for long periods of time. The pleasure of eating white rice might be suppressed by their financial problems that occurred because of buying electrical products, agricultural equipment, automobiles, and food. The editorial office concluded that a self-sufficient society had been replaced by a consuming society.

\section{Acknowledgements}

The author would like to thank Mr. Norio Nakamura for his knowledge about the Kunohe District. Ms. Natsuko Komurata helped the author to cook the supper (Fig. 2b).

Author's contributions

TM is the sole author of this paper. The author(s) read and approved the final manuscript.

Funding

No funding was received for this research.

Availability of data and materials

All data are presented in the main text.

Competing interests

The author declares no competing interests.

Received: 17 March 2020 Accepted: 20 August 2020

Published online: 04 September 2020

References

1. Japan Zone. Japanese food: the basics. https://www.japan-zone.com/ culture/food.shtml. Accessed 8 Aug 2020

2. Gabriel AS, Ninomiya K, Uneyama H. The role of the Japanese traditional diet in healthy and sustainable dietary patterns around the world. Nutrients. 2018;10:173

3. Seura T, Fukuwatari T. Japanese diet score is associated with gut microbiota composition in young Japanese adults. Journal of Nutritional Science and Vitaminology. 2019;65:414-20.

4. Yabuno T. Japanese barnyard millet (Echinochloa utilis, poaceae) in Japan. Economic Botany. 1987;41:484-93.

5. Editorial office. Records of folk's voice Part 1. Iwate no Hoken. 1953;33:46 [in Japanese].

6. Iwate Prefecture official travel guide, Visit Iwate. Mochi Cuisine, Ichinoseki City. https://visitiwate.com/article/4842. Accessed 8 Aug 2020.

7. Editorial office. Special issue of food habits. I think this way. Response from the questionnaire. Iwate no Hoken. 1955;39:41-50 [in Japanese].

8. Hosono H. Daily life in poverty. Iwate no Hoken. 1960;57:6-23 [in Japanese].

9. Editorial office. I think this way. Response from the questionnaire on dietary habits change in rural area. Iwate no Hoken. 1969:83:57-64 [in Japanese].

10. Shoji Kondo. What are dietary habits for anti-aging? (1) Iwate no Hoken 1956:45:37-47, (2) 1957:46:53-60, (3) 1957;47:57-64. [in Japanese].

11. Kinoshita S. Life of charcoal families. Immigrating from mountain to mountain to cut trees. 1959;56:6-29 [in Japanese].

12. Tagaki R. Pale and inactive facies. Iwate no Hoken. 1962;63:14-8 [in Japanese].

13. Miura T. My life so far - working in settle land, which is necessary for cultivation of mind. Iwate no Hoken. 1960;58:6-23 [in Japanese].

14. Sasahara R. Memories at that time. Because I could not eat white rice. Iwate no Hoken. 1960;59:54-5 [in Japanese].

15. Iwate Nippo (newspaper). A cash box of Kunohe District; labours outside of the hometown. 7 April 1953. [in Japanese].

16. Hatakeyama T. When does come the day when parents and children can spend together? Iwate no Hoken. 1964;70:40-50 [in Japanese].

17. Tsuchikura Y. I wanted to know out of the community. Iwate no Hoken. 1965;73:6-9 [in Japanese].

18. Sekiguchi M. Becoming desolate in mountainous area. Iwate no Hoken. 1968;80:15-9 [in Japanese].

19. Editorial office. I think this way. Response from the questionnaire on dietary change in rural community. Iwate no Hoken. 1955;39:41-50 [in Japanese].

\section{Publisher's Note}

Springer Nature remains neutral with regard to jurisdictional claims in published maps and institutional affiliations. 